\title{
Neural network modeling of the photocatalytic degradation of 2,4-dihydroxybenzoic acid in aqueous solution
}

\author{
E. Oliveros ${ }^{1, *}$, F. Benoit-Marquié ${ }^{2}$, E. Puech-Costes ${ }^{2}$, M.T. Maurette ${ }^{2}$ and C.A.O. Nascimento ${ }^{3}$ \\ ${ }^{1}$ Lehrstuhl für Umweltmesstechnik, Engler-Bunte-Institut, Universität Karlsruhe, 76128 Karlsruhe, Germany \\ ${ }^{2}$ Laboratoire des IMRCP, Université Paul Sabatier, 31062 Toulouse Cedex, France \\ ${ }^{3}$ Escola Politecnica, Universidade de São Paulo, 01000 São Paulo, SP, Brazil
}

\begin{abstract}
Artificial neural networks have been used for modeling the $\mathrm{TiO}_{2}$ photocatalytic degradation of 2,4-dihydroxybenzoic acid, chosen as a model water contaminant, as a function of the concentrations of substrate and catalyst. The experimental design methodology was applied to the choice of an appropriate set of experiments well distributed in the experimental region (Doehlert uniform array). Contrary to a classical treatment of the data, based on apparent rate constants modeled by a quadratic polynomial function, neural network analysis of the same experimental data does not require the use of any kinetic or phenomenological equations and allows the simulation and the prediction of the pollutant degradation as a function of irradiation time, as well as prediction of reaction rates, under varying conditions within the experimental region.
\end{abstract}

Key words. Artificial neural networks - 2,4-dihydroxybenzoic acid (DHBA) - experimental design - modeling - photocatalytic degradation $-\mathrm{TiO}_{2}$.

\section{Introduction}

Photocatalytic oxidative degradation of organic pollutants in aerated aqueous solutions using $\mathrm{TiO}_{2}$ dispersions has attracted considerable interest during the last decade [1-4]. $\mathrm{TiO}_{2}$ photocatalysis is considered as one of the promising Advanced Oxidation Processes (AOP) for remediation of industrial waste waters and ground waters contaminated with non biodegradable and/or toxic chemicals.

Adsorption phenomena and absorption of incident radiation play a critical role in heterogeneous photocatalysis and are largely dependent on the experimental conditions. At low substrate concentrations, the initial degradation rate usually follows a Langmuir-Hinshelwood adsorption type kinetic model (see e.g. [5,6], and substrate degradation as a function of irradiation time may be fitted to simple apparent kinetic orders (pseudo-zero [7] or first-order [8]), as observed for a number of aromatic compounds [9,10]. A rigorous kinetic approach has shown, however, that the observed disappearance of the substrate may follow kinetics of different orders depending on experimental conditions (especially catalyst and substrate concentrations) and that the experimental error may result in confusing a rather complex dependence with a simple one [11]. Complex degradation kinetics may result, for example, in the case of the photocatalytic treatment of highly charged industrial waste waters, where competitive absorption of UV radiation by $\mathrm{TiO}_{2}$ and by e.g. aromatic substances occurs.

During the last decade, the number of applications of artificial neural networks has been growing steadily for classification (pattern recognition, spectra, medical categories, customer/market profiles, ...), forecasting (sales, stock-market, economic indicators, prediction of any time based vari- able...), and for predictive modeling (process control, dynamic systems, robot control, ...) $[12,13]$. In spite of their extremely simplified structure compared to biological neural networks, artificial neural networks are able to mimic some of the information processing and learning abilities of the human brain. They have the ability to "learn" and record linear and non linear behaviors of a system from a set of experimental data (e.g., processing conditions and corresponding response(s)). They do not require the knowledge of the physical and chemical laws that govern the system. Therefore, they may be extremely useful for simulating complex processes, such as photochemical processes [14,15], which would otherwise be very difficult to model using differential phenomenological equations.

In a previous publication [16], we have reported the modeling of the effects of the concentrations of $\mathrm{TiO}_{2}$ and of 2,4dihydroxybenzoic acid (DHBA), chosen as a model pollutant, on the degradation rate of DHBA. The experiments were planned according to the experimental design methodology which provides the means for building a statistically significant model of a phenomenon by performing a minimum set of appropriately chosen experiments [17-19]. We have shown [16] that a Doehlert uniform array associated to a quadratic polynomial model may be used to adequately represent the efficiency of the $\mathrm{TiO}_{2}$ photocatalytic degradation of DHBA in aqueous solutions in the concentration ranges investigated. However, two empirical models had to be used: a kinetic model for representing the DHBA disappearance as a function of time $\left(k_{\mathrm{ap}}\right)$ and a polynomial model for the variation of $k_{\mathrm{ap}}$ as a function of the $\mathrm{TiO}_{2}$ and the initial DHBA concentrations. We report here the analysis of the same series of planned experiments using artificial neural networks which do not require the use of any kinetic or

* Correspondence and reprints.

Received January 27, 1998; revised July 15, 1998; accepted July 31, 1998. 
phenomenological equations [20]. Therefore, direct modeling of the DHBA disappearance as a function of irradiation time in the different experimental conditions investigated was possible.

\section{Materials and methods}

\section{Experimentation}

The experimental set-up used for the photocatalytic degradation of DHBA and the analytical procedures have already been described in detail [16]. Briefly, irradiation was carried out in an annular reactor containing $0.25 \mathrm{~L}$ of solution at a temperature of $20( \pm 0.5){ }^{\circ} \mathrm{C}$. A medium pressure mercury arc (Philips HPK $125 \mathrm{~W}$ ) was positioned in the axis of the reactor. The solution was magnetically stirred before and during irradiation and permanently saturated with oxygen. The DHBA concentration was varied between $210 \mathrm{mg} \mathrm{L}^{-1}(1.36$ $\left.\times 10^{-3} \mathrm{~mol} \mathrm{~L}^{-1}\right)$ and $594 \mathrm{mg} \mathrm{L}^{-1}\left(3.9 \times 10^{-3} \mathrm{~mol} \mathrm{~L}^{-1}\right)$ and that of $\mathrm{TiO}_{2}$ between $1.75 \mathrm{~g} \mathrm{~L}^{-1}$ and $4.25 \mathrm{~g} \mathrm{~L}^{-1}$. Samples of the reaction mixture were taken at regular time intervals during irradiation, filtered and analyzed by HPLC in order to determine DHBA concentrations in solution as a function of irradiation time (total irradiation time: 3 hours).

Adsorption experiments in the dark were performed in order to determine the DHBA fraction adsorbed on the $\mathrm{TiO}_{2}$ surface at equilibrium. The $\mathrm{TiO}_{2}$ and DHBA concentrations for these experiments were identical to those used for the irradiation experiments. The solutions were stirred for 3 hours, and samples taken at regular time intervals were filtered and analyzed by absorption spectrophotometry. Adsorption equilibrium was reached within 10 minutes (or less) in all cases, and we found that on average $6.7 \mathrm{mg}$ of DHBA were adsorbed per $\mathrm{g}$ of $\mathrm{TiO}_{2}$ (standard deviation: $1.3 \mathrm{mg}$ ), whatever the concentrations of DHBA and $\mathrm{TiO}_{2}$ in the ranges investigated. This value was used for calculating the initial concentration of DHBA in solution at adsorption equilibrium $\left([\mathrm{DHBA}]_{0, \mathrm{eq}}\right)$, in cases where it was not measured experimentally.

\section{Experimental data acquisition for neural network modeling}

Experimental data used for the neural network calculations were obtained by performing the series of designed experiments (Doehlert uniform array) reported in 16. The 7 experiments to be performed in the case of two variables (here the initial concentration of DHBA introduced, $[\mathrm{DHBA}]_{0}$, and the $\mathrm{TiO}_{2}$ concentration, $\left[\mathrm{TiO}_{2}\right]$, are uniformly distributed and, in coded variables, may be represented by the apexes and the center of a hexagon (Tab. I). An additional control experiment was carried out (experiment 8) and the experiment at the center of the experimental region was repeated three times (experiment 7). For each experiment, the DHBA concentrations in solution at various irradiation times ([DHBA $\left.]_{t}\right)$ were determined by HPLC (vide supra). From the replications at the center, the standard error for $[\mathrm{DHBA}]_{t}$ was estimated to be $\pm 20 \mathrm{mg} \mathrm{L}^{-1}$. Therefore, measured values of [DHBA] $]_{t}$ lower than $20 \mathrm{mg} \mathrm{L}^{-1}$ were not included in the calculations. Results are listed in Table II.
Table I. Initial concentration of DHBA introduced ([DHBA $\left.]_{0}, U_{l}\right)$ and $\mathrm{TiO}_{2}$ concentration $\left(\left[\mathrm{TiO}_{2}\right], U_{2}\right)$ for the experiments of the Doehlert uniform array (Nos. 1 to 7) and for the control experiment (No. 8) (corresponding values of coded variables for the Doehlert matrix, $X_{i}$, are also given).

\begin{tabular}{ccccc}
\hline $\begin{array}{c}\text { Experiment } \\
\text { No. }\end{array}$ & $\begin{array}{c}{[\mathrm{DHBA}]_{0}} \\
U_{1}\left(\mathrm{mg} \mathrm{L}^{-1}\right)\end{array}$ & $\begin{array}{c}{\left[\mathrm{TiO}_{2}\right]} \\
U_{2}\left(g \mathrm{~L}^{-1}\right)\end{array}$ & $X_{1} *$ & $X_{2} *$ \\
\hline 1 & 594 & 3 & 1 & 0 \\
2 & 210 & 3 & -1 & 0 \\
3 & 498 & 4.25 & 0.5 & 0.866 \\
4 & 306 & 1.75 & -0.5 & -0.866 \\
5 & 498 & 1.75 & 0.5 & -0.866 \\
6 & 306 & 4.25 & -0.5 & 0.866 \\
7 & 402 & 3 & 0 & 0 \\
8 & 350 & 2 & -0.27 & -0.69 \\
\hline
\end{tabular}

$* X_{i}=\left(U_{i}-U_{i 0}\right) / \Delta U_{\mathrm{i}}$ where $U_{\mathrm{i} 0}$ is the value of $U_{i}$ at the center of the experimental region $\left(=\left(U_{i, \text { max }}+U_{i, \text { min }}\right) / 2\right)$ and $\Delta U_{\mathrm{i}}$ the step $\left(=\left(U_{i, \max }-U^{i, \min }\right) / 2\right)$.

Table II. Concentrations of DHBA in solution at various irradiation times $\left([\mathrm{DHBA}]_{t}\right.$, output variable chosen for the neural network calculations) for the experiments of the Doehlert uniform array (Nos. 1 to 7) and for the control experiment (No. 8) $\left([\mathrm{DHBA}]_{t=0}=\right.$ $\left.[\mathrm{DHBA}]_{0}\right)$.

\begin{tabular}{|c|c|c|c|c|c|c|c|}
\hline \multicolumn{2}{|c|}{$\begin{array}{c}\text { No. } 1 \\
\text { Time }[D H B A]_{t} \\
\text { (min) }\left(m g L^{-1}\right)\end{array}$} & \multicolumn{2}{|c|}{$\begin{array}{c}\text { No. } 2 \\
\text { Time }[D H B A]_{t} \\
\text { (min) }\left(m g L^{-1}\right)\end{array}$} & \multicolumn{2}{|c|}{$\begin{array}{c}\text { No. } 3 \\
\text { Time }[D H B A]_{t} \\
\text { (min) }\left(m g L^{-1}\right)\end{array}$} & \multicolumn{2}{|c|}{$\begin{array}{c}\text { No. } 4 \\
\text { Time }[D H B A]_{t} \\
\text { (min) }\left(m g L^{-1}\right)\end{array}$} \\
\hline 0 & 594 & 0 & 200 & 0 & 498 & 0 & 306 \\
\hline 15 & 546 & 15 & 123 & 16 & 426 & 25 & 251 \\
\hline 45 & 476 & 30 & 91 & 30 & 372 & 45 & 176 \\
\hline 59 & 422 & 45 & 51 & 47 & 349 & 63 & 144 \\
\hline 75 & 387 & 60 & 20 & 59 & 320 & 81 & 94 \\
\hline 90 & 363 & & & 75 & 266 & 100 & 63 \\
\hline 105 & 315 & & & 90 & 229 & 127 & 20 \\
\hline 120 & 278 & & & 107 & 202 & & \\
\hline \multirow[t]{3}{*}{180} & 182 & & & 120 & 177 & & \\
\hline & & & & 150 & 120 & & \\
\hline & & & & 180 & 45 & & \\
\hline \multicolumn{2}{|c|}{ No. 5} & \multicolumn{2}{|c|}{ No. 6} & \multicolumn{2}{|c|}{$\begin{array}{c}\text { No. } 7 \\
\text { (average values) }\end{array}$} & \multicolumn{2}{|c|}{$\begin{array}{c}\text { No. } 8 \\
\text { (control) }\end{array}$} \\
\hline \multicolumn{2}{|c|}{$\begin{array}{l}\text { Time }[D H B A]_{t} \\
(\min )\left(m g L^{-1}\right)\end{array}$} & \multicolumn{2}{|c|}{$\begin{array}{l}\text { Time }[D H B A]_{t} \\
(\min )\left(\mathrm{mg} \mathrm{L}^{-1}\right)\end{array}$} & $\begin{array}{l}\text { Time } \\
\text { (min) }\end{array}$ & $\begin{array}{l}{[D H B A]_{t}} \\
\left(m g L^{-1}\right)\end{array}$ & $\begin{array}{l}\text { Time } \\
\text { (min) }\end{array}$ & $\begin{array}{l}{[D H B A]_{t}} \\
\left(m g L^{-1}\right)\end{array}$ \\
\hline 0 & 498 & 0 & 306 & 0 & 402 & 0 & 350 \\
\hline 15 & 445 & 19 & 211 & 15 & 343 & 5 & 324 \\
\hline 30 & 388 & 40 & 162 & 30 & 292 & 15 & 312 \\
\hline 50 & 345 & 60 & 116 & 45 & 238 & 30 & 266 \\
\hline 60 & 296 & 80 & 57 & 60 & 222 & 45 & 221 \\
\hline 76 & 285 & & & 75 & 186 & 61 & 187 \\
\hline 90 & 251 & & & 90 & 157 & 90 & 109 \\
\hline 105 & 225 & & & 105 & 120 & & \\
\hline 120 & 211 & & & 120 & 81 & & \\
\hline 150 & 171 & & & & & & \\
\hline 180 & 118 & & & & & & \\
\hline
\end{tabular}




\section{Original articles}

\section{Artificial neural networks}

\section{Neural network structure}

In general, an artificial neural network consists of processing units (nodes or neurons) and information flow channels between the neurons, usually denominated interconnects. The most widely used networks for modeling purposes (non dynamic models) are "feed-forward" networks in which information propagates only in one direction, consisting of three layers: input, hidden and output layers (Fig. 1). The neurons in the input layer (boxes in Fig. 1) store the independent (input) variables $\left(x_{i}\right)$ which are characteristic of the system investigated.

Each processing neuron (circles in Fig. 1) in the hidden layer first calculates the weighed sum of all interconnected signals from the input layer plus a bias term $\left(S_{j}\right.$, Eq. (1)), and then generates an output $\left(O_{j}\right)$ through its activation function (e.g. a sigma function $f(\alpha)$, Eq. (2)).

$$
S_{j}=\sum_{i=1}^{n} w_{i, j} x_{i}+w_{n+1, j}
$$

where $S_{j}$ is the input of the $j$-neuron of the hidden layer, $w_{i, j}$, the weight between the $i$-neuron of the input layer and the $j$-neuron of the hidden layer, $x_{i}$, the normalized input variable to the $i$-neuron.

$$
\begin{gathered}
O_{j}=f\left(S_{j}\right) \\
\text { with } f(\alpha)=1 /\left(1+\mathrm{e}^{-\alpha}\right) .
\end{gathered}
$$

Similarly, each processing neuron (circles in Fig. 1) in the output layer calculates the weighed sum of all interconnected signals from the hidden layer plus a bias term $\left(S_{k}\right.$, Eq. (3)), and then generates an output $\left(O_{k}\right)$ through the sigma function.

$$
S_{k}=\sum_{j=1}^{m} w_{j, k} O_{j}+w_{m+1, k}
$$

where $w_{j, k}$ is the weight between the $j$-neuron of the hidden layer and the $k$-neuron of the output layer and $m$ is the number of neurons in the hidden layer.

The network output consists of one value (or more generally of a series of values), $O_{k}$, which represents the response variable (or response variables) calculated by the network.

\section{Neural network training}

The network "learns" by making changes in its weights in order to reach a convergence between the response values $O_{k}$ calculated by the network and the experimental responses $y_{k}$. At present, the most extensively adopted algorithm for the learning phase is the back-propagation algorithm [12,13], which is a generalization of the steepest descent method. A series of normalized input-output pairs of experimental data $(x, y)$ are used for training the network (training set) and the weights $\left(w_{u, v}\right)$ are modified by an iterative technique in order to minimize the quadratic deviation $E$ defined as:

$$
E=\sum_{l=1}^{r} \sum_{k=1}^{p}\left(y_{k}^{(l)}-O_{k}^{(l)}\right)^{2}
$$

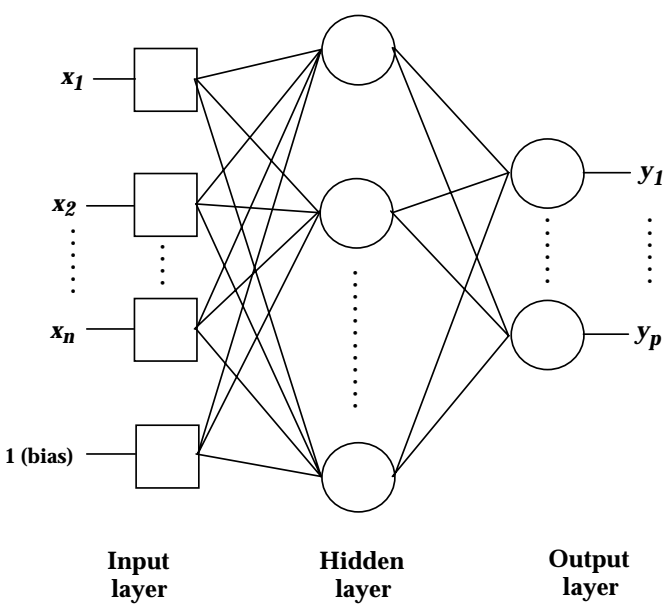

Fig. 1. Structure of a "feed-forward" artificial neural network.

where $p$ is the number of output variables and $r$ the number of input-output pairs of experimental data.

In the back-propagation algorithm, the weights between the hidden and output layers are adjusted first at each iteration (training cycle). Subsequently, the weights between the input and hidden layers are changed. After presentation of the first input-output pair, the second pair is processed and so on. More details on the specific procedure used in this work may be found in [14,21,22]. For testing the network, only values of the input variables are fed to the network and the quadratic deviation is calculated (Eq. (4)) as a measure of the predictive capacity of the given network. The network is tested and validated by comparing its predicted output values with the experimental values on an independent set of data (test set).

The success in obtaining a reliable and robust network depends strongly on a judicious choice of the process variables involved, as well as on the available set of experimental data used for training purposes $[13,14]$. In particular, it is extremely important for suitable neural network modeling that the input data be adequately distributed in the experimental region. The experimental design methodology may therefore be advantageously applied to the choice of an appropriate set of experiments, the data being subsequently treated using both a classical polynomial model and neural network modeling. Such an approach was also proposed for PC-based software, combining the use of central composite or simplex designs with neural network analysis [23]. Recently, the use of neural networks was proposed for selecting optimal experimental designs and the experimental design methodology was applied to the optimization of neural network parameters [24].

\section{Results and discussion}

\section{Neural network development}

The neural network software used in this work was developed by one of the authors (C.A.O. Nascimento, [14]). 


\section{Input and output variables}

Three input variables to the network have been chosen:

- the concentration of DHBA introduced in the aqueous solution $\left(U_{l}=[\mathrm{DHBA}]_{0}\right)$,

- the concentration of $\mathrm{TiO}_{2}\left(U_{2}=\left[\mathrm{TiO}_{2}\right]\right)$ and

- the irradiation time $\left(U_{3}=t\right)$.

In the present case, $[\mathrm{DHBA}]_{t}$ is the only output variable. Normalized values of input and output variables $\left(x_{i}\right.$ and $y$, respectively) have been used in equations (1) to (4). Variables have been normalized in the range 0.1 to 0.9 as shown in equation (5) for input variables.

$x_{i}=0.1+\left(U_{i}-U_{i, \min }\right)(0.9-0.1) /\left(U_{i, \max }-U_{i, \min }\right)$.

The minimum and maximum values of each variable are given in Table III.

For given values of $[\mathrm{DHBA}]_{0}$ and $\left[\mathrm{TiO}_{2}\right]$, i.e. for each experimental point of the Doehlert array (experiments 1 to 7, Tab. I), there are a series of input-output pairs of experimental data $(x, y)$ for the neural network which correspond to the different irradiation times (Tab. II). Note that, in the present case, there is only one neuron in the output layer of the neural network, since there is only one output variable $\left([\mathrm{DHBA}]_{t}\right)$. For the neural network calculations, the concentration of DHBA in solution at $t=0\left([\mathrm{DHBA}]_{t=0}\right)$ was taken equal to $[\mathrm{DHBA}]_{0}$ or to $[\mathrm{DHBA}]_{0, \mathrm{eq}}$ (concentration of DHBA in solution at adsorption equilibrium, see Experimentation).

\section{Neural network training}

One input-output pair of data $(x, y)$ for training the network consisted of 4 values (three for the input variables $x$ $\left([\mathrm{DHBA}]_{0},\left[\mathrm{TiO}_{2}\right], t\right)$ and one for the corresponding output variable $\left.y\left([\mathrm{DHBA}]_{t}\right)\right)$. Results at different irradiation times for a given experiment (chosen among experiments 1 to 7 , Tab. II) have been distributed into the training set and the test set. In general, data at times $t=0$ and $t=180 \mathrm{~min}$ (or time $t$ corresponding to the smallest [DHBA] $]_{t}$ measured) have been included into the training set and intermediate data have been alternatively put into the training and test sets (two replications of experiment No. 7 have been used). Among the 66 pairs of data used, 40 have been included into the training set and 26 into the test set.

As mentioned in the previous paragraph, neural network calculations were carried out using $[\mathrm{DHBA}]_{t=0}=[\mathrm{DHBA}]_{0}$ or $[\mathrm{DHBA}]_{t=0}=[\mathrm{DHBA}]_{0, \mathrm{eq}}$. Despite the fact that in principle

Table III. Minimum and maximum values of input and output variables for the calculation of the normalized values of the neural network input $\left(x_{i}\right)$ and output variables $(y)$ (Eq. (5)).

\begin{tabular}{lcccc}
\hline & $\begin{array}{c}{[\mathrm{DHBA}]_{0}} \\
U_{1}\left(\mathrm{mg} \mathrm{L}^{-1}\right)\end{array}$ & $\begin{array}{c}{\left[\mathrm{TiO}_{2}\right]} \\
U_{2}\left(\mathrm{~g} \mathrm{~L}^{-1}\right)\end{array}$ & $\begin{array}{c}t \\
U_{3}(\min )\end{array}$ & $\begin{array}{c}{[\mathrm{DHBA}]_{t}} \\
\left(\mathrm{mg} \mathrm{L}^{-1}\right)\end{array}$ \\
\hline$U_{i, \text { min }}$ & 200 & 1.75 & 0 & - \\
$U_{i, \text { max }}$ & 600 & 4.25 & 180 & - \\
{$[\mathrm{DHBA}]_{t, \text { min }}$} & - & - & - & 0 \\
{$[\mathrm{DHBA}]_{t, \max }$} & - & - & - & $588^{\mathrm{a}}$ \\
\hline
\end{tabular}

${ }^{\text {a }}$ Corresponds to $[\mathrm{DHBA}]_{t=0}=[\mathrm{DHBA}]_{0, \mathrm{eq}}$ at $[\mathrm{DHBA}]_{0}=600 \mathrm{mg} \mathrm{L}^{-1}$. these two informations should be equivalent for the network, we obtained better results for fitting the data as well as for prediction (with the same number of neurons in the hidden layer and the same number of training cycles) when using $[\mathrm{DHBA}]_{t=0}=[\mathrm{DHBA}]_{0, \mathrm{eq}}$, in particular for the control experiment No. 8 which was included neither in the training set nor in the test set.

An important step in the calculation process is the determination of the adequate number of neurons in the hidden layer, according to the criterion of minimum quadratic deviation between the experimental results and the calculated outputs from the network (Eq. (4)), whilst avoiding over-fitting problems $[13,25]$. This may be achieved by using a minimum number of neurons in the hidden layer as well as an adequate number of training cycles, which provide the lowest error in the test set. In the present work, it has been found that the use of 4 neurons in the hidden layer with 20000 training cycles provided the best results. Similar results have been obtained by using up to 6 neurons in the hidden layer. With 4 neurons, a total of 21 weights are calculated: 16 between the input and hidden layers ( 3 weights plus a bias for each neuron of the hidden layer) and 5 between the hidden and output layers (4 weights plus a bias). The corresponding weights obtained from the training set are given in matrices $W_{1}$ and $W_{2}$ respectively. Note that the test set was only used as a control and not for calculating the weights.

$$
W_{1}=\left|\begin{array}{cccc}
5.57 & 1.97 & -0.017 & -1.17 \\
0.230 & -0.515 & 1.92 & 1.52 \\
0.348 & -1.91 & -2.44 & 0.993 \\
0.997 & 0.941 & 0.473 & 0.988
\end{array}\right| W_{2}=\mid \begin{array}{r}
-2.94 \\
-5.79 \\
5.22 \\
2.65 \\
0.776
\end{array}
$$

Figure 2 shows a good fit between the ensemble of exper imental values of $[\mathrm{DHBA}]_{t}$ (taking into account experimen tal error) and the corresponding values calculated for the training set and the test set with the 4 neurons network, using the weights listed in matrices $W_{1}$ and $W_{2}$.

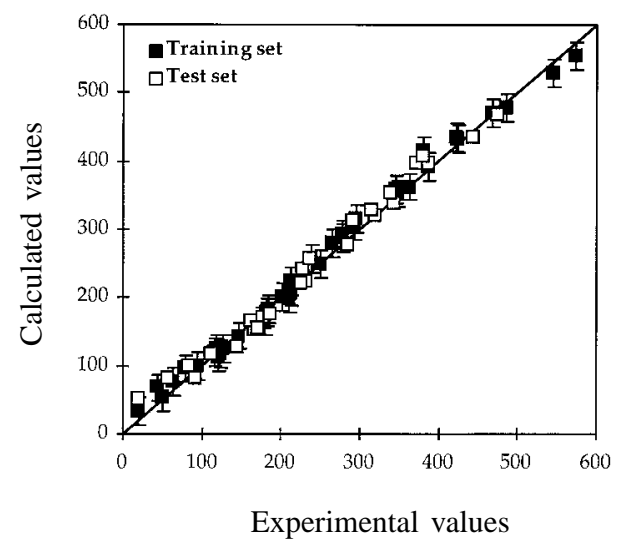

Fig. 2. Values of the concentration of DHBA at various irradiation times $\left([\mathrm{DHBA}]_{t}\right)$ calculated for the training set and for the test set by the 4 neurons network (matrices of weights $W_{1}$ and $W_{2}$ ) as a function of the corresponding experimental values. 


\section{Original articles}

\section{Neural network simulation}

In Figure 3, we have represented the plots of $[\mathrm{DHBA}]_{t}$ as a function of irradiation time for experiments Nos. 1 to 4 and experiment No. 7, including experimental values of $[\mathrm{DHBA}]_{t}$ and values calculated for the training set and the test set with the 4 neurons network.

Figure 4 shows the neural network predicted values of $[\mathrm{DHBA}]_{t}$ as a function of irradiation time for control experiment No. 8, compared to experimental values. Within experimental error, a reasonable fit is also observed in this case, although this experiment was neither included in the training set nor in the test set.

The neural network allows prediction of the DHBA concentration in solution at any irradiation time within the limits of the experimental region investigated. Using these data, initial rates of DHBA degradation have been computed for a series of combinations of $\left[\mathrm{TiO}_{2}\right]$ and $[\mathrm{DHBA}]_{0}$ in this same experimental region. Figure 5 shows a three-dimensional representation of the initial rate response surface. The highest initial degradation rates have been found for concentrations of $\mathrm{TiO}_{2}$ between 2.25 and $2.75 \mathrm{~g} \mathrm{~L}^{-1}$ and initial concentrations of DHBA between $280 \mathrm{mg} \mathrm{L}^{-1}$ and $320 \mathrm{mg} \mathrm{L}^{-1}$. In this domain, the best compromise is found between $[\mathrm{DHBA}]_{0}$ and $\left[\mathrm{TiO}_{2}\right]$, so that the incident radiation is mainly absorbed by the photocatalyst. Increasing $[\mathrm{DHBA}]_{0}$ leads to competing absorption by DHBA and thus to inner filter effects which slow down the DHBA degradation rate because of the low efficiency of DHBA photolysis [16]. Whereas increasing $\left[\mathrm{TiO}_{2}\right]$ above the concentration where maximum absorption of the incident radiation by the catalyst occurs, leads to a leveling off of the degradation rate [15,26-29].

\section{Comparison of neural network and classical experimental design analyses}

As indicated in the Introduction, in our previous publication [16], we have used the experimental design methodology for modeling the efficiency of DHBA degradation by $\mathrm{TiO}_{2}$ photocatalysis, as a function of the $\mathrm{TiO}_{2}$ and the initial DHBA concentrations $\left(\left[\mathrm{TiO}_{2}\right]\right.$ and $[\mathrm{DHBA}]_{0}$, controlled variables). The experiments were designed according to a Doehlert uniform array (Tab. I) which is associated to a quadratic polynomial model and allows modeling of curve response surfaces $[18,19]$. Briefly, the procedure involved the following steps, also summarized in Table IV:

- The disappearance of DHBA as a function of the irradiation time was measured for the series of designed experiments (Tab. I).

- The apparent rate constant of DHBA disappearance $\left(k_{\mathrm{ap}}\right)$ was chosen as an experimental response to represent the efficiency of DHBA degradation: the best fits for the ensemble of experiments were obtained using an apparent order of 0.5 for the DHBA concentration (Eq. (6)).

$$
[\mathrm{DHBA}]^{0.5}=[\mathrm{DHBA}]_{0}^{0.5}-\left(k_{\mathrm{ap}} / 2\right) t
$$

- The coefficients of the quadratic polynomial model representing the variations of $k_{\text {ap }}$ as a function of $\left[\mathrm{TiO}_{2}\right]$ and $[\mathrm{DHBA}]_{0}$ (Eq. (7)) were calculated by the least-square method (regression analysis) [30].

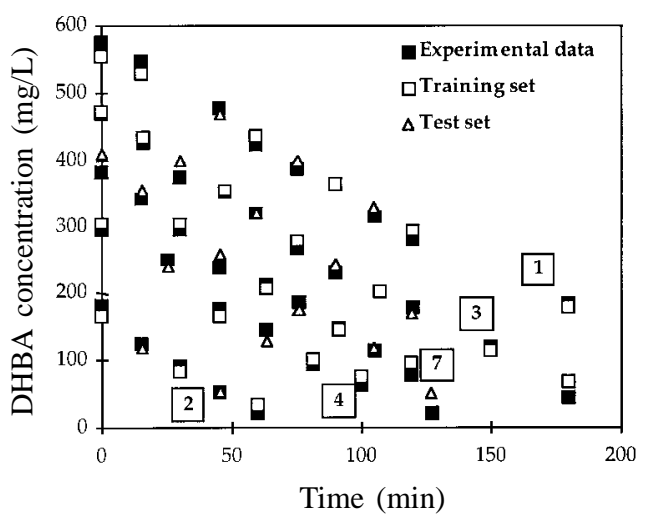

Fig. 3. Evolution of the DHBA concentration as a function of irradiation time for experiments Nos. 1 to 4 and experiment No. 7: experimental values, as well as values calculated for the training set and the test set by the 4 neurons network, are indicated.

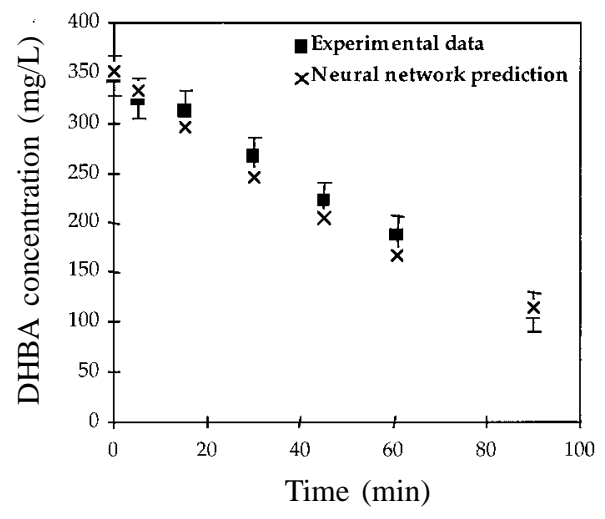

Fig. 4. Comparison of neural network prediction and experimental data for control experiment No. 8 .

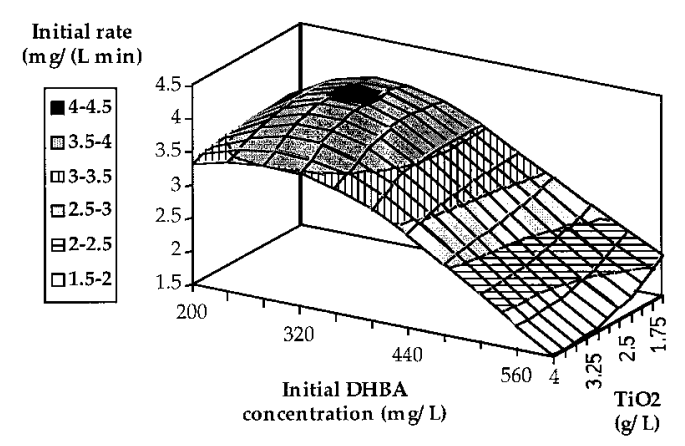

Fig. 5. Three-dimensional representation of the variation of initial rates of DHBA degradation as a function of the $\mathrm{TiO}_{2}$ amount and the DHBA initial concentration (4 neurons network, weights given in matrices $W_{1}$ and $W_{2}$ ).

$$
\begin{aligned}
k_{\text {ap }}= & b_{0}+b_{1} X_{1}+b_{2} X_{2}+b_{11} X_{1}^{2}+b_{22}^{2} X_{2}^{2}+b_{12} X_{1} X_{2} \\
= & 0.175-0.099 X_{1}+0.022 X_{2}+0.052 X_{1}^{2} \\
& -0.013 X_{2}^{2}-0.016 X_{1} X_{2}
\end{aligned}
$$

where $X_{1}$ and $X_{2}$ are the coded (centered and reduced) variables representing $[\mathrm{DHBA}]_{0}$ and $\left[\mathrm{TiO}_{2}\right]$, respectively (Tab. I). 


\section{Original articles}

Table IV. Comparison of classical experimental design and neural network analyses of the efficiency of DHBA degradation by photocatalysis as a function of $[\mathrm{DHBA}]_{0}$ and $\left[\mathrm{TiO}_{2}\right](t$ : irradiation time).

Experimental design analysis (polynomial model)

\begin{tabular}{|c|c|c|c|c|}
\hline $\begin{array}{l}\text { Controlled } \\
\text { variables }\end{array}$ & $\begin{array}{l}\text { Experimental } \\
\text { data }\end{array}$ & $\begin{array}{l}\text { Experimental } \\
\text { response }\end{array}$ & $\begin{array}{l}\text { Polynomial } \\
\text { model }\end{array}$ & $\begin{array}{l}\text { After validation, } \\
\text { prediction of }\end{array}$ \\
\hline $\begin{array}{l}{[\mathrm{DHBA}]_{0}} \\
{\left[\mathrm{TiO}_{2}\right]}\end{array}$ & $\begin{array}{l}{[\text { DHBA }]=f(t) \text { for }} \\
\text { the } 7 \text { experiments } \\
\text { of the Doehlert matrix, } \\
\text { plus } 2 \text { replications }\end{array}$ & $\begin{array}{c}k_{\mathrm{ap}} \\
\text { deduced from kinetic } \\
\text { model for each of } \\
\text { the designed experiments } \\
\text { (9 values, i.e. } 9 \text { variables- } \\
\text { response data pairs) }\end{array}$ & $k_{\mathrm{ap}}=f\left([\mathrm{DHBA}]_{0},\left[\mathrm{TiO}_{2}\right]\right)$ & $\begin{array}{c}k_{\mathrm{ap}} \\
\text { for any }[\mathrm{DHBA}]_{0} \text { and }\left[\mathrm{TiO}_{2}\right] \\
\text { in the experimental region } \\
\text { investigated }\end{array}$ \\
\hline \multicolumn{5}{|c|}{ Neural network analysis (simulation) } \\
\hline $\begin{array}{l}\text { Input } \\
\text { variables }\end{array}$ & $\begin{array}{l}\text { Experimental } \\
\text { data }\end{array}$ & $\begin{array}{c}\text { Output } \\
\text { variable }\end{array}$ & $\begin{array}{l}\text { Neural network } \\
\text { training }\end{array}$ & $\begin{array}{l}\text { After validation, } \\
\text { simulation of }\end{array}$ \\
\hline $\begin{array}{l}{[\mathrm{DHBA}]_{0}} \\
{\left[\mathrm{TiO}_{2}\right]} \\
t\end{array}$ & $\begin{array}{l}\text { [DHBA] }=f(t) \\
\text { for the } 7 \text { experiments } \\
\text { of the Doehlert matrix, } \\
\text { plus } 2 \text { replications) }\end{array}$ & $\begin{array}{c}{[\mathrm{DHBA}]_{t}} \\
(66 \text { values, i.e. } \\
66 \text { input-output data pairs })\end{array}$ & Matrices of weights & $\begin{array}{c}{[\mathrm{DHBA}]=f(t)} \\
\text { for any }[\mathrm{DHBA}]_{0} \text { and }\left[\mathrm{TiO}_{2}\right] \\
\text { in the experimental region } \\
\text { investigated }\end{array}$ \\
\hline
\end{tabular}

- Values of $k_{\text {ap }}$ calculated with the model were in good agreement with results of the experiments used to estimate the coefficients of the model, as well as with those of the control experiment (No. 8) (Tab. I).

- The contour plot (curves of constant response) and the three-dimensional response surface for $k_{\text {ap }}$ were represented. Two main conclusions were reached as a result of this study: in the range of concentrations investigated, the influence of $[\mathrm{DHBA}]_{0}$ is more important than that of the concentration of $\mathrm{TiO}_{2}$; at high $\mathrm{TiO}_{2}$ concentrations, a plateau is reached for the degradation efficiency so that no benefit is obtained by increasing the $\mathrm{TiO}_{2}$ concentration above $3.5 \mathrm{~g} \mathrm{~L}^{-1}$, these observations being in agreement with literature results.

A neural network approach would not have been possible using $k_{\text {ap }}$ as an output variable, due the limited number of input-output data pairs ( 7 different experimental points) in this case [13]. However, using as output variable the DHBA concentration measured at each irradiation time for each of the seven experiments of the Doehlert matrix ([DHBA $]_{t}$ ) provided a much larger number of input-output data pairs (Tab. IV). We have shown that, under those conditions, the neural network, once trained, is able to simulate the kinetics of DHBA disappearance without the use of any empirical model. Although the data are highly correlated in our case, good simulations may be obtained provided that the number of neurons in the hidden layer and the number of training cycles are adequately chosen $[13,25]$. The fact that no mathematical model is necessary represents one of the main advantages of the neural network approach: indeed in cases where no common order may be found for the disappearance of the substrate of interest (which could arise for a larger range of substrate concentrations), the choice of an experimental response for the polynomial model (Eq. (7)) is difficult (a possible choice would be the concentration of sustrate remaining at a given irradiation time, but a large amount of information is then lost leading to larger errors on the coefficients of the polynomial model). It should be noted however that in the neural network approach it is very difficult to interpret the values of the weights in terms of the relative influence of the different input variables on the phenomenon investigated, due to the important interconnection of the different signals transmitted between input, hidden and output layers (Eqs. (1) and (3)) [13]. The use of a global representation of the kinetics (by an apparent rate constant for example) has the advantage of giving the possibility to compare contributions of linear and quadratic terms in the polynomial model (degree of curvature) and to evaluate the relative influence of the different variables. The comparison between neural network and experimental design analyses in the context of the present work is summarized in table IV.

\section{Conclusion}

We have modeled the degradation efficiency of a model water pollutant (DHBA) by $\mathrm{TiO}_{2}$ photocatalysis, as a function of the $\mathrm{TiO}_{2}$ and the initial DHBA concentrations, using the combination of experimental design methodology [16] and neural network analysis. In the experimental design approach, a global analysis was carried out using the apparent rate constant of pollutant disappearance $\left(k_{\mathrm{ap}}\right)$ to represent the degradation efficieny. In this work, we have shown that neural network analysis of the same experimental data allows simulation of the evolution of the DHBA concentration as a function of irradiation time, as well as prediction of reaction rates, under any conditions within the experimental region investigated. Development of processes for the degradation of organic contaminants in industrial waste waters at pilot and/or production levels requires the optimization of experimental conditions, so that a given volume of contaminated water may be treated in the required period of time at a minimum cost [15,31]. A combination of designed experiments, which are well distributed in the experimental region, and of data analysis by both polynomial models and artificial neural networks, may be of great 


\section{Original articles}

help in decreasing experimentation time and costs for optimization. We have also successfully followed this strategy for the modeling and optimization of a light-enhanced Fenton reaction applied to the oxidative degradation of organic contaminants in aqueous solutions [20].

\section{Acknowledgements}

The authors gratefully acknowledge financial support of this work by the "Conseil Régional de Midi-Pyrénées". F. B.-M. thanks ADEME (Agence pour le Développement et la Maîtrise de l'Énergie) for a grant and EO is very grateful to the DAAD (PROBRAL, Deutscher Akamedischer Austauschdienst, Germany) and FAPESP (Fundaçao de Amparo à Pesquisa do Estado de São Paulo, Brazil) for supporting her stay in São Paulo.

\section{References}

1. Serpone, N.; Pelizzetti, E. Photocatalysis, Fundamentals and Applications, Wiley, New York, 1989.

2. Legrini, O.; Oliveros, E.; Braun, A. M. Chem. Rev. 1993, 93, 671-698.

3. Ollis, D. F.; Al-Ekabi, H. Photocatalytic Purification and Treatment of Water and Air, Elsevier Science BV, Amsterdam, 1993.

4. Zepp, R. G.; Crosby, D. G. Aquatic and Surface Chemistry, Lewis Publischers, Boca Raton, 1994.

5. Mills, A.; Holland, C. E.; Davies, R. H.; Worsley, D. J. Photochem. Photobiol. A: Chem. 1994, 83, 257-263.

6. Wei, T. Y.; Wan, C. C. J. Photochem. Photobiol. A: Chem. 1992, 69, 241-249.

7. Al-Ekabi, H.; Serpone, N.; Pelizzetti, E.; Minero, C.; Fox, M. A.; Barton Draper, R. Langmuir 1989, 5, 250-255.

8. Matthews, R. W. J. Phys. Chem. 1987, 91, 3328-3333.

9. Matthews, R. W. Aust. J. Chem. 1987, 940, 667-675.

10. Matthews, R. W. Solar. Energy 1987, 38, 405-413.

11. Minero, C. Solar Energy Mat. Solar Cells 1995, 38, 421-430.

12. Rumelhart, D. E.; Hinton, G. E.; Williams, R. J. In: Parallel Distributed Processing: Explorations in the Microstructure of Cognition, McClelland, J. L. Ed. Foundations Rumelhart DE, Bradford Books, The MIT Press, Cambridge, Mass., 1986, Vol. 1, Chap. 8.

13. Zupan, J.; Gasteiger, J. Neural Networks for Chemists: An Introduction, VCH, Weinheim, 1993.

14. Nascimento, C. A. O.; Oliveros, E.; Braun, A. M. Chem. Eng. Proc. 1994, 33, 319-324
15. Jacob, L.; Oliveros, E.; Legrini, O.; Braun, A. M. In: Photocatalytic Purification and Treatment of Water and Air, Ollis, D. F.; Al-Ekabi, H. Eds., Elsevier Science Publishers, 1993; pp 511-532.

16. Benoit-Marquié, F.; Puech-Costes, E.; Braun, A. M.; Oliveros, E.; Maurette, M. T.; J. Photochem. Photobiol. A: Chem. 1997, 108, 65-71.

17. Fargin, E.; Sergent, M.; Mathieu, D.; Phan-Tan-Luu, R. Bio. Sci. 1985, 4, 77-82, and references cited therein.

18. Box, G. E. P.; Hunter, W. G.; Hunter, J. S. Statistics for Experimenters: An Introduction to Design, Data Analysis and Model Building, Wiley, New York, 1978.

19. Khuri, A. I.; Cornell, J. A. Response Surfaces, Designs and Analyses, Dekker, M. Ed., ASQC Quality Press, New York, 1987.

20. Oliveros, E.; Göb, S.; Benoit-Marquié, F.; Puech-Costes, E.; Maurette, M. T.; Nascimento C.A.O. Modelling of photochemical processes for water treatment using experimental design and artificial neural networks, Chimiométrie 97. Expériences et modèles, Lyon (France), 3-5 December 1997, Proceedings "Communications Affichées", Poster P28.

21. Chan, W. M.; Nascimento, C. A. O. J. Appl. Pol. Sci. 1994, 53, 1277-1289.

22. Nascimento, C. A. O.; Guardani, R.; Giulietti, M. Powder Technol. 1997, 90, 89-94.

23. Owens, A. J.; Mocella, M. T. In: Artificial Neural Networks, Prieto, A. Ed., International Workshop IWANN'91 (Granada, Spain) Proceedings, Lectures in Computer Science 540, Springer Verlag, New York, 1991; pp 227-234.

24. Courtois, S.; Phan-Tan-Luu, R. Chimiométrie 97. Expériences et modèles, Lyon (France), 3-5 December 1997, Proceedings «Communications Orales », C12; Id., Proceedings «Communications Affichées », P34.

25. Pollard, J. D.; Broussard, M. R.; Garrison, D. B.; San, K. Y. Comput Chem. Eng. 1992, 16, 253-258.

26. Augugliaro, V.; Palmisano, L.; Sclafani, A.; Minero, C.; Pelizzetti, E. Toxicol. Environ. Chem. 1988, 16, 89-109.

27. Ollis, D. F.; Pelizzetti, E. In: Photocatalysis, Fundamentals and Applications, Serpone, N.; Pelizzetti, E. Eds., Wiley, New York, 1989; pp 603-637.

28. Turchi, C. S.; Ollis, D. F. J. Catal. 1989, 119, 483-496.

29. Wei, T. Y.; Wan, C. C. Ind. Eng. Chem. Res. 1991, 30, 12931300.

30. Mathieu, D.; Phan-Tan-Luu, R.; L. P. R. A. I., Université d'Aix-Marseille, France, NEMROD software (version 3.0) 1995.

31. Oliveros, E.; Legrini, O.; Hohl, M.; Müller, T.; Braun, A. M. Chem. Eng. Proc. 1997, 36, 397-405. 